\title{
Survival Following Palliative External-beam Radiotherapy of Locally Advanced and Metastatic Liver Cancer
}

\author{
DIRK RADES ${ }^{1}$, LOUISA BOLM ${ }^{1}$, STEVEN E. SCHILD $^{2}$ and TOBIAS BARTSCHT ${ }^{3}$ \\ Departments of ${ }^{1}$ Radiation Oncology and ${ }^{3}$ Hematology and Oncology, University of Lübeck, Lübeck, Germany; \\ ${ }^{2}$ Department of Radiation Oncology, Mayo Clinic, Scottsdale, AZ, U.S.A.
}

\begin{abstract}
Aim: The goal of this study was to identify prognostic factors of survival in patients receiving palliative external-beam radiotherapy (EBRT) for advanced liver cancer. Patients and Methods: Seventeen patients irradiated for advanced liver cancer were retrospectively evaluated. Fourteen patients had metastatic disease, three had locally advanced disease. Six variables were investigated for survival: age at $E B R T$, time from liver cancer diagnosis to EBRT, number of involved metastatic sites, gender, Eastern Cooperative Oncology Group (ECOG) performance score, radiation dose. Results: On univariate analyses, time from liver cancer diagnosis to EBRT $>12$ months ( $p=0.040$ ), only 0-1 metastatic sites $(p=0.003)$ and ECOG performance score $1-2(p<0.001)$ were positively correlated with survival. On Cox regression analysis, the number of metastatic sites (risk ratio $=4.68$, $p=0.053$ ) and ECOG performance score (risk ratio $=4.68$, $p=0.056)$ showed a strong trend for association with survival. Conclusion: Predictors of survival were found that can facilitate choosing the optimal treatment for individual patients with liver cancer assigned to palliative EBRT.
\end{abstract}

Primary liver cancer is most commonly treated with surgery, radiofrequency ablation (RFA) or trans-arterial chemoembolization (TACE), whereas external-beam radiotherapy (EBRT) plays only a minor role $(1,2)$. However, in cases of locally advanced or metastatic disease, EBRT may be a reasonable option $(3,4)$. Since EBRT is seldom administered to patients with liver cancer, only few data are available. These data suggest that many patients with advanced liver cancer who are not suitable for surgery, RFA or TACE and

Correspondence to: Dirk Rades, MD, Department of Radiation Oncology, University of Lübeck, Lübeck, Ratzeburger Allee 160, D-23538 Lübeck, Germany. Tel: +49 4515006661, Fax: +49 4515003324, e-mail: Rades.Dirk@gmx.net

Key Words: Liver cancer, advanced disease, palliative treatment, external-beam radiotherapy, survival. who are assigned to EBRT have a poor survival prognosis and are considered highly palliative cases (3-5). However, a few patients may live considerably longer. It is of importance to identify these patients who may benefit from more intensive treatment regimens in order to avoid under-treatment. In addition, the detection of patients with an extraordinarily poor survival prognosis would help prevent these patients from receiving too much anticancer treatment, particularly when taking into account their short remaining lifespan. This approach would be considerably facilitated if prognostic factors that allow estimation of a patient's survival time were available. Therefore, this study was conducted with the aim of identifying predictors of survival in patients receiving EBRT for locally or systemically advanced liver cancer.

\section{Patients and Methods}

Seventeen unselected patients irradiated for locally advanced or metastatic liver cancer (hepatocellular carcinoma) were included in this retrospective study. Fourteen patients were irradiated for metastatic disease, namely spinal cord compression in eight patients, brain metastases in four, and for painful bone metastases in two. Three patients were irradiated locoregionally to the liver for non-resectable locally advanced disease. A total of six clinical variables were investigated in the entire series of 17 patients to identify their potential impact on survival: age at the time of irradiation $(<70$ versus $\geq 70$ years; median $=70$ years), time from liver cancer diagnosis to palliative irradiation ( $\leq 12$ versus $>12$ months), number of involved metastatic sites (organs) (0-1 versus $\geq 2$ sites), gender, Eastern Cooperative Oncology Group (ECOG) performance score (ECOG 1-2 versus 3-4) and total radiation dose given as equivalent dose in 2 Gy fractions (EQD2) ( $<25$ Gy versus $>30$ Gy). The investigated clinical variables and the corresponding distributions are shown in Table I.

For univariate analyses of survival, the Kaplan-Meier method and the log-rank test were applied (6). Those clinical variables that proved to be significant $(p<0.05)$ were afterwards evaluated in a multivariate manner with a Cox regression analysis.

\section{Results}

On univariate analyses (Table II), time from liver cancer diagnosis to irradiation of $>12$ months $(p=0.040$; Figure 1$)$, 
Table I. Investigated variables and their distributions.

\begin{tabular}{lcc}
\hline & $\begin{array}{c}\text { Number of } \\
\text { patients }\end{array}$ & $\begin{array}{c}\text { Proportion } \\
(\%)\end{array}$ \\
\hline Age & 8 & 47 \\
$\quad<70$ years & 9 & 53 \\
$\quad \geq 70$ years & & \\
Time from liver cancer & 13 & 76 \\
diagnosis to irradiation & 4 & 24 \\
$\quad \leq 12$ Months & 6 & 35 \\
$\quad>12$ Months & 11 & 65 \\
Number of metastatic sites & 2 & 12 \\
$\quad 0-1$ & 15 & 88 \\
$\quad 22$ & & \\
Gender & 8 & 47 \\
$\quad$ Female & 9 & 53 \\
$\quad$ Male & & \\
ECOG performance score & 8 & 47 \\
$\quad 1-2$ & 9 & 53 \\
$\quad 3-4$ & & \\
Total radiation dose (EQD2) & & \\
$\quad<25$ Gy & & \\
$\quad>30$ Gy &
\end{tabular}

ECOG: Eastern Cooperative Oncology Group, EQD2: equivalent dose in $2 \mathrm{~Gy}$ fractions.

involvement of only $0-1$ metastatic sites $(p=0.003$; Figure 2$)$ and an ECOG performance score of 1-2 $(p<0.001$; Figure 3$)$ were significantly correlated with a better survival. On Cox regression analysis, 0-1 involved metastatic sites (risk ratio $=4.68,95 \%$ confidence interval $=0.98-37.37 ; p=0.053$ ) and an ECOG performance score of 1-2 (risk ratio $=4.68$, $95 \%$ confidence interval $=0.97-39.34 ; p=0.056)$ showed a strong trend for association. The time from liver cancer diagnosis to irradiation of $>12$ months was not significant (risk ratio $=2.44,95 \%$ confidence interval $=0.24-29.41$; $p=0.44$ ) on Cox regression analysis.

The 6-month survival rate of the five patients with two favorable prognostic factors, i.e. 0-1 involved metastatic sites and an ECOG performance score of 1-2, was $100 \%$. In contrast, all patients with two unfavorable prognostic factors, i.e. $\geq 2$ metastatic sites and an ECOG performance score of 3-4, died within 5 months following EBRT; the 3-month survival rates was $12.5 \%$. The 3 - and 6-month survival rates of the four patients with one favorable and one unfavorable prognostic factor were $50 \%$ and $25 \%$, respectively.

\section{Discussion}

The number of patients with liver cancer is constantly increasing and, therefore, these patients are increasingly becoming the focus of anticancer research (7-11). Most patients presenting with locally or systemically advanced
Table II. Univariate analysis of survival.

\begin{tabular}{lcccc}
\hline & \multicolumn{3}{c}{ Survival (\%) at } & \\
\cline { 2 - 3 } & 3 Months 6 Months 12 Months & $p$-Value \\
\hline Age & & & & \\
$\quad<70$ Years & 50 & 38 & 19 & \\
$\quad \geq 70$ Years & 44 & 33 & 33 & 0.81 \\
Time from liver cancer & & & & \\
diagnosis to irradiation & 31 & 15 & 15 & \\
$\quad \leq 12$ Months & 47 & 35 & 28 & $\mathbf{0 . 0 4 0}$ \\
$\quad>12$ Months & & & & \\
Number of metastatic sites & 83 & 83 & 63 & \\
$\quad 0-1$ & 27 & 9 & 9 & 0.003 \\
$\quad 22$ & & & & \\
Gender & 50 & 50 & 50 & \\
$\quad$ Female & 47 & 33 & 25 & 0.92 \\
$\quad$ Male & & & & \\
ECOG performance score & 88 & 75 & 60 & \\
$\quad$ 1-2 & 11 & 0 & 0 & $<\mathbf{0 . 0 0 1}$ \\
$\quad 3-4$ & & & & \\
Total radiation dose (EQD2) & 25 & 25 & 25 & \multirow{2}{*}{0.36} \\
$\quad<25$ Gy & 67 & 44 & 33 & \\
$\quad>30$ Gy & 47 & 35 & 28 & \\
Entire cohort & & & & \\
\hline
\end{tabular}

ECOG: Eastern Cooperative Oncology Group, EQD2: equivalent dose in $2 \mathrm{~Gy}$ fractions. Bold values represent significant $p$-values.

primary liver cancer have a poor prognosis, particularly patients with metastatic disease (3-5). Palliative EBRT can be a reasonable option in order to achieve relief of debilitating symptoms or to avoid potential complications (35). If EBRT is indicated, physicians can choose from several dose-fractionation regimens including single-fraction programs, multi-fraction programs with short overall treatment times of one week or less and multi-fraction programs lasting up to several weeks. The optimal palliative treatment always requires consideration of individual patientrelated factors including the patient's preferences, and social and economic situations, as well as their remaining lifespan. For patients from studies including different cancer types who were irradiated for metastatic disease such as malignant spinal cord compression and brain metastases, it has been reported that those patients with a short expected survival time generally should receive a short EBRT program, whereas potential long-term survivors could benefit from more protracted EBRT regimens in terms of more favorable treatment outcomes and less late morbidity (12-16). Therefore, particularly to avoid over- or under-treatment of patients requiring palliative EBRT, a patient's survival prognosis should be included in the process of decisionmaking regarding their optimal treatment. This also applies to patients assigned to palliative EBRT for locally or 


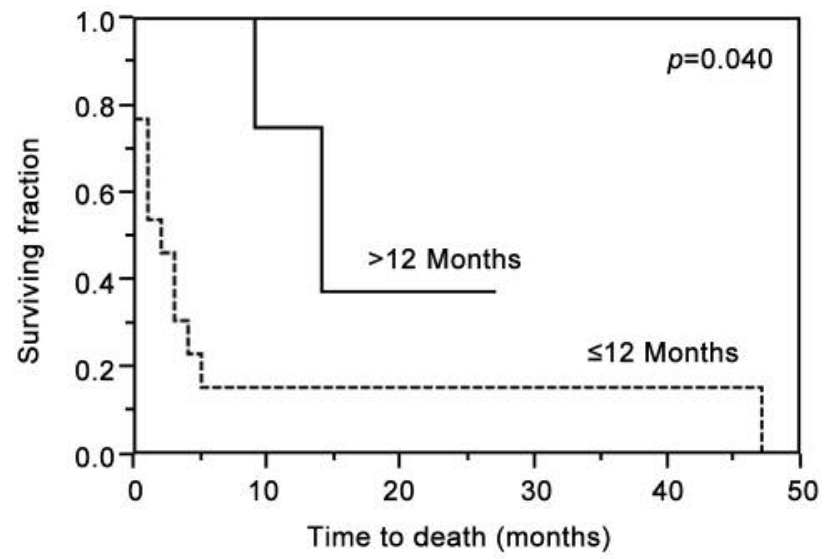

Figure 1. Impact of the time from liver cancer diagnosis to irradiation ( $\leq 12$ vs. $>12$ months) on survival (univariate analysis).

systemically advanced liver cancer (3-5). Therefore, this study aimed to identify prognostic factors of survival in these patients in order to improve the individualization of their treatment. Two predictors were identified that were significantly associated with survival on univariate analysis and were of borderline significance for association with survival on Cox regression analysis, namely the number of involved metastatic sites and the ECOG performance score.

Patients in whom both these prognostic factors were unfavorable had a 3 -month survival rate of only $12.5 \%$ and a 6 -month survival rate of $0 \%$. Therefore, these patients can be considered good candidates for EBRT with a short overall treatment time $(13,15-18)$. Depending on the patient's symptoms, even best supportive care may be reasonable. Patients with one favorable and one unfavorable prognostic factor had a 3-month survival rate of $50 \%$ and a 6-month survival rate of $25 \%$, respectively. According to previous studies in patients irradiated for cancer metastases, the patients of this intermediate prognostic group appear appropriately treated with longer-course multi-fraction EBRT, for example with $30 \mathrm{~Gy}$ given in 10 fractions over 2 weeks (12-18). Finally, for those patients of the present study who had a favorable number of metastatic sites and a favorable ECOG performance score, the 3-month and 6-month survival rates were $100 \%$ and the 12 -month survival rate was $75 \%$. Taking into account this favorable prognosis, these patients would likely benefit from longer-course EBRT with higher total doses and lower doses per fraction. Higher total doses were reported to result in improved local control and survival in patients irradiated for malignant spinal cord compression or brain metastases $(12,14,17,18)$. Furthermore, lower doses per fraction were reported to result in less EBRT-related late morbidity, which becomes more important in long-term

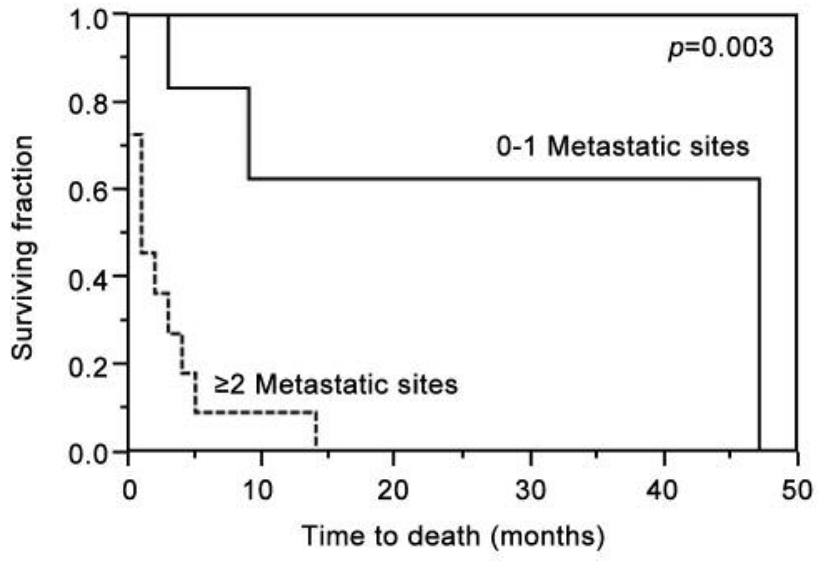

Figure 2. Impact of the number of involved metastatic sites (0-1 vs. $\geq 2$ sites) on survival (univariate analysis).

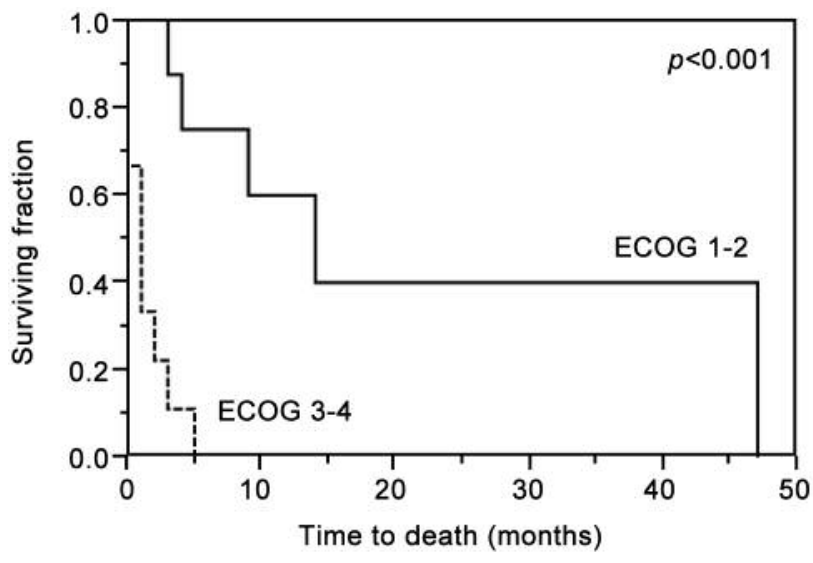

Figure 3. Impact of the Eastern Cooperative Oncology Group (ECOG) performance score (ECOG 1-2 vs. 3-4) on survival (univariate analysis).

survivors (19). When following these recommendations, one should keep in mind the retrospective nature of the data used for this study and the relatively small patient cohort. However, since patients receiving palliative EBRT for locally advanced or metastatic liver cancer are relatively rare, a larger prospective study will not be likely soon.

In conclusion, two clinical factors predictive of survival in patients treated with palliative EBRT for locally advanced or metastatic liver cancer were identified. These factors were the number of involved metastatic sites and the ECOG performance score. Given the limitations of this study, recommendations for an individualized treatment approach could be made for such patients based on these two factors 


\section{Conflicts of Interest}

On behalf of all Authors, the corresponding Author states that there is no conflict of interest related to this study.

\section{References}

1 Harada N, Maeda T, Yoshizumi T, Ikeda T, Kayashima H, Ikegami T, Harimoto N, Takaki S and Maehara Y: Laparoscopic liver resection is a feasible treatment for patients with hepatocellular carcinoma and portal hypertension. Anticancer Res 36: 3489-3497, 2016.

2 Akinwande $\mathrm{O}$, Philips $\mathrm{P}$, Scoggins $\mathrm{C}$ and Martin RC: Radioembolization versus chemoembolization (DEBDOX) for the treatment of unresectable hepatocellular carcinoma: A propensity matched study. Anticancer Res 36: 239-246, 2016.

3 Rades D, Dahlke M, Janssen S, Gebauer N and Bartscht T: Radiation therapy for metastatic spinal cord compression in patients with hepatocellular carcinoma. In Vivo 29: 749-752, 2015.

4 Kang MK, Kim MS, Kim SK, Ye GW, Lee HJ, Kim TN and Eun JR: High-dose radiotherapy with intensity-modulated radiation therapy for advanced hepatocellular carcinoma. Tumori 97: 724$731,2011$.

5 Goodwin CR, Yanamadala V, Ruiz-Valls A, Abu-Bonsrah N, Shankar G, Sankey EW, Boone C, Clarke MJ, Bilsky M, Laufer I, Fisher C, Shin JH and Sciubba DM: A systematic review of metastatic hepatocellular carcinoma to the spine. World Neurosurg 91: 510-517.e4, 2016.

6 Kaplan EL and Meier P: Non parametric estimation from incomplete observations. J Am Stat Assoc 53: 457-481, 1958.

7 Cheng CC, Liu YH, Lai YCC, Hsu YH, Chao WT and Lai YS: Hypoacetylation in association with histone 3 modulation in human hepatocellular carcinoma. In Vivo 29: 237-242, 2015.

8 Shen J, Yeh CC, Wang Q, Gurvich I, Siegel AB and Santella RM: Plasma adiponectin and hepatocellular carcinoma survival among patients without liver transplantation. Anticancer Res 36: 5307-5314, 2016.

9 Aliberti C, Carandina R, Sarti D, Mulazzani L, Catalano V, Felicioli A, Coschiera P and Fiorentini G: Hepatic arterial infusion of polyethylene glycol drug-eluting beads for primary and metastatic liver cancer therapy. Anticancer Res 36: 3515$3521,2016$.

10 Enomoto H, Nakamura H, Liu W, Iwata Y, Nishikawa H, Takata R, Yoh K, Hasegawa K, Ishii A, Takashima T, Sakai Y, Aizawa $\mathrm{N}$, Ikeda N, Iijima $\mathrm{H}$ and Nishiguchi S: Down-regulation of HDGF inhibits the growth of hepatocellular carcinoma cells in vitro and in vivo. Anticancer Res 35: 6475-6479, 2015.
11 Miller KD, Siegel RL, Lin CC, Mariotto AB, Kramer JL, Rowland JH, Stein KD, Alteri R and Jemal A: Cancer treatment and survivorship statistics, 2016. CA Cancer J Clin 66: 271-289, 2016.

12 Rades D, Panzner A, Dziggel L, Haatanen T, Lohynska R and Schild SE: Dose-escalation of whole-brain radiotherapy for brain metastasis in patients with a favorable survival prognosis, Cancer 118: 3853-3859, 2012.

13 Rades D, Kieckebusch S, Lohynska R, Veninga T, Stalpers LJ, Dunst $\mathrm{J}$ and Schild SE: Reduction of overall treatment time in patients irradiated for more than three brain metastases. Int J Radiat Oncol Biol Phys 69: 1509-1513, 2007.

14 Rades D, Panzner A, Rudat V, Karstens JH and Schild SE: Dose escalation of radiotherapy for metastatic spinal cord compression (MSCC) in patients with relatively favorable survival prognosis. Strahlenther Onkol 187: 729-735, 2011.

15 Rades D, Stalpers LJ, Veninga T, Schulte R, Hoskin PJ, Obralic N, Bajrovic A, Rudat V, Schwarz R, Hulshof MC, Poortmans P and Schild SE: Evaluation of five radiation schedules and prognostic factors for metastatic spinal cord compression. J Clin Oncol 23: 3366-3375, 2005.

16 Rades D, Šegedin B, Conde-Moreno AJ, Garcia R, Perpar A, Metz M, Badakhshi H, Schreiber A, Nitsche M, Hipp P, Schulze W, Adamietz IA, Norkus D, Rudat V, Cacicedo J and Schild SE: Radiotherapy with $4 \mathrm{~Gy} \times 5$ versus $3 \mathrm{~Gy} \times 10$ for metastatic epidural spinal cord compression: Final results of the SCORE-2 trial (ARO 2009/01). J Clin Oncol 34: 597-602, 2016.

17 Rades D, Douglas S, Veninga T, Stalpers LJA, Hoskin PJ, Bajrovic A, Adamietz IA, Basic H, Dunst $J$ and Schild SE: Validation and simplification of a score predicting survival in patients irradiated for metastatic spinal cord compression. Cancer 116: 3670-3673, 2010.

18 Dziggel L, Segedin B, Podvrsnik NH, Oblak I, Schild SE and Rades D: Validation of a survival score for patients treated with whole-brain radiotherapy for brain metastases. Strahlenther Onkol 189: 364-366, 2013.

19 DeAngelis LM, Delattre JY and Posner JB: Radiation-induced dementia in patients cured of brain metastases. Neurology 39 : 789-796, 1989. 